\title{
FINE NEEDLE ASPIRATION CYTOLOGY IN LYMPH NODES WITH SPECIAL REFERENCE TO TUBERCULOUS LYMPHADENOPATHY
}

\author{
Maninder Jeet Singh ${ }^{1}$, Surabhi Solanki², Sarandeep Singh Puri ${ }^{3}$, P. S. Dhot ${ }^{4}$, Parul Singhal 5 \\ 13rd Year Postgraduate Student, Department of Pathology, Saraswathi Institute of Medical Sciences, Hapur, U. P. \\ 2Tutor, Department of Pathology, Saraswathi Institute of Medical Sciences, Hapur, U. P. \\ ${ }^{3}$ Assistant Professor, Department of Pathology, Saraswathi Institute of Medical Sciences, Hapur, U. P. \\ ${ }^{4}$ Professor and HOD, Department of Pathology, Saraswathi Institute of Medical Sciences, Hapur, U. P. \\ 5Professor, Department of Pathology, Saraswathi Institute of Medical Sciences, Hapur, U. P.
}

\section{ABSTRACT}

\section{BACKGROUND}

FNAC provides an alternative to excision biopsy for lymph nodes and is an easy procedure for collection of material for cytomorphological and bacteriological examination.

Aims and Objectives- To analyse the utility and diagnostic importance of FNAC in lymph node disease. To assess the cytomorphological features and incidence of various lymph nodes diseases on FNAC. To study the cytomorphological pattern of tuberculous lymphadenitis in the population in and around SIMS. To correlate the acid fast bacilli [AFB] positivity with cytomorphological patterns.

\section{MATERIALS AND METHODS}

The study was a descriptive cross-sectional study carried out from July 2016 to June 2017 in Department of Pathology, Saraswathi Institute of Medical Sciences, Anwarpur, Pilkhuwa, Hapur, U. P. The inclusion criteria included patients with clinical presentation of lymph node enlargement with non-specific complaints. All patients were of age group 20 - 60 years. Consent to participate in the test was taken. Fine needle aspiration cytology (FNAC) was performed on enrolled patients by the pathologist. The following staining methods were used: May-Grunwald-Giemsa Staining, Papanicolaou Staining and Ziehl-Neelsen Staining.

\section{RESULTS}

In this study a total number of 100 cases of lymphadenopathy were studied, out of which $95 \%$ were benign and $5 \%$ were malignant. In our study, most common lesion on cytology was found to be tuberculous lymphadenitis (40\%). In the present study, the lesions were seen in all age group ranging from 20 years with a mean age of 35.64 years. Maximum cases were seen between 20 - 30 years. Out of 100 cases, $46 \%$ were male and 54\% were female with significant female preponderance; 23:27 (M: F) sex ratio was observed. In our study, cervical lymph nodes (70\%) were frequently involved. Tuberculous lymphadenitis was seen in 15 out of 40 (55.6\%). Correlation between AFB positivity with cytomorphological patterns was seen in 36 out of 40 cases.

\section{CONCLUSION}

FNAC can be performed as an outpatient department procedure. The procedure is safe, well accepted by patients, very cost effective and requires minimum instrumentation in comparison to excision biopsy.

\section{KEY WORDS}

FNAC, Lymph Nodes, Tuberculous.

HOW TO CITE THIS ARTICLE: Singh MJ, Solanki S, Puri SS, et al. Fine needle aspiration cytology in lymph nodes with special reference to tuberculous lymphadenopathy. J. Evolution Med. Dent. Sci. 2018;7(20):2437-2441, DOI: 10.14260/jemds/2018/548

\section{BACKGROUND}

Fine needle aspiration cytology (FNAC) is a safe, cost effective and conclusive procedure. ${ }^{1}$ Lymph nodes are an integral component of the immune system and are a common presentation in the clinical practice. Cervical lymphadenopathy is a common clinical finding and may be sign of an indolent inflammation, infection or a malignant disorder, depending upon many factors including the geographical condition and socio-economical setup. ${ }^{2-4}$ In our country, infective (tubercular) lymphadenopathy is quite common.

'Financial or Other Competing Interest': None.

Submission 24-02-2018, Peer Review 26-04-2018,

Acceptance 02-05-2018, Published 14-05-2018.

Corresponding Author:

Dr. Sarandeep Singh Puri,

R-12/72, Raj Nagar,

Ghaziabad-201001, Uttar Pradesh.

E-mail: drsarandeep147@gmail.com

DOI: $10.14260 /$ jemds $/ 2018 / 548$
Although, histopathology is considered as gold standard criteria for lymph node sampling, but FNAC has potential benefits over the other diagnostic modalities like simplicity, minimal trauma and minimal complication and easy availability of results that have made it a frequently practiced investigation in the initial diagnosis and follow-up of primary lymph node malignancies and in following patients with other malignancies and identifying metastasis or recurrence. .-6 $^{-1}$

FNAC provides an alternative to excision biopsy for lymph nodes and is an easy procedure for collection of material for cytomorphological and bacteriological examination. ${ }^{7}$

Tuberculosis (TB) is an infectious disease caused by various strains of mycobacteria, usually Mycobacterium Tuberculosis in humans. It is an airborne disease and most commonly affect lungs where it is called Pulmonary Tuberculosis. One-third of the world's population is currently infected, and more than 1.5 million people die each year due to tuberculosis. Among these, about $15-20 \%$ of cases are 
reported as having only extrapulmonary involvement where the infection occurs in other parts of the body. ${ }^{8}$

In previous years a number of studies had been conducted on different aspects of Tuberculosis in western part of Uttar Pradesh, but no such study has been carried out in SIMS Hospital which mainly covers a rural based population. This study was conducted to describe the cytomorphological features and percentage of various lymph nodes diseases on FNAC and to assess correlation between FNAC and ZN staining in diagnosis of tuberculous lymphadenitis.

\section{Objectives}

- To assess the cytomorphological features and incidence of various lymph nodes diseases on FNAC.

- $\quad$ To study the cytomorphological pattern of Tuberculous lymphadenitis in the population in and around SIMS.

- To correlate the acid fast bacilli [AFB] positivity with cytomorphological patterns.

\section{MATERIALS AND METHODS \\ Study Design}

The study was a descriptive study.

\section{Study Period}

The study period was from July 2016 to June 2017 .

\section{Study Place}

Department of Pathology, Saraswathi Institute of Medical Sciences, Anwarpur, Pilkhuwa, Hapur, U. P.

\section{Inclusion Criteria}

Patient with clinical presentation of lymph node enlargement with non-specific complaints. All patients of age group 20 - 60 years, clinically suspected cases of tubercular lymphadenitis. Cases with representative and adequate cellularity. Consent to participate in the test.

\section{Exclusion Criteria}

- Patient not willing to participate in the study.

- Swelling other than lymph node origin.

- Swelling size less than $5 \mathrm{~cm}$.

- Patient undergoing treatment for any other chronic disease.

\section{Sample Size}

Patients fulfilling all inclusion and exclusion criteria was enrolled in the study. A written informed consent was obtained from all subjects before their enrolment in the study.

\section{Method of Collection of Data}

Aspiration of the lymph node was done after eliciting detailed history of the patient, i.e. age, sex, site and duration of involvement, any other investigations performed, thorough clinical examination.

\section{Study Tools}

Procedure and Methodology.

The study was performed after approval by hospital ethical committee. Hundred patients were included in the study. Patients with clinical presentation were reviewed.
Patient's presentation such as the size, location and character of adenopathy along with any associated physical findings were assessed. Erythema, tenderness, warmth and fluctuance suggests lymphadenitis and node that is fixed (non-moveable), matted together. Fine needle aspiration cytology (FNAC) was performed on enrolled patients by the Pathologist. Aspiration of enlarged lymph node was performed on enrolled patients by the Pathologist. Aspiration of enlarged lymph node was performed free hand using a 23-G needle mounted on a Cameco handle. The swellings were made prominent. They were cleaned with $70 \%$ isopropyl alcohol. Aspirated material after preparing smears on the glass slides are fixed in $95 \%$ ethyl alcohol for staining.

\section{The following Staining Methods were used}

1. May-Grunwald-Giemsa Staining.

2. Papanicolaou Staining.

3. Ziehl-Neelsen Staining.

\section{Statistical Analysis}

All data was collected and verified. Collected data was subjected to SPSS (version 20) for analysis. Data was expressed as frequencies for all the parameter; Chi-square test was performed to visualise the difference. $P$ value of 0.05 was considered significant.

\section{RESULTS}

\begin{tabular}{|c|c|c|}
\hline Gender & Number & Percent \\
\hline Female & 54 & 54 \\
\hline Male & 46 & 46 \\
\hline \multicolumn{2}{|r|}{ Table 1. Gender-Wise Distribution } \\
\hline
\end{tabular}

Out of total 100 cases, 46 were male patients and remaining 54 were females.

\begin{tabular}{|c|c|c|c|}
\hline \multirow{2}{*}{} & \multicolumn{2}{|c|}{ Unilateral } & \multirow{2}{*}{ Bilateral } \\
\cline { 2 - 3 } & Right & Left & 7 \\
\hline Frequency & 48 & 45 & 7.0 \\
\hline Percent & 48.0 & 45.0 & \\
\hline \multicolumn{3}{|c|}{ Table 2. Site Distribution } \\
\hline
\end{tabular}

Most of the lymphadenopathy cases were unilateral and out of which $48 \%$ were from right side and $45 \%$ were from left side and remaining $7 \%$ were bilateral.

\begin{tabular}{|c|c|c|}
\hline Location & Frequency & Percent \\
\hline Abdominal wall & 1 & 1.0 \\
\hline Axilla & 5 & 5.0 \\
\hline Breast & 1 & 1.0 \\
\hline Cervical & 70 & 70.0 \\
\hline Chest wall & 1 & 1.0 \\
\hline Inguinal & 1 & 1.0 \\
\hline Mandible & 1 & 1.0 \\
\hline Neck & 3 & 3.0 \\
\hline Submandibular region & 9 & 9.0 \\
\hline Submental & 8 & 8.0 \\
\hline Table 3. Location of Affected Lymph Nodes \\
\hline
\end{tabular}

In this cervical lymphadenopathy was most commonly involved lymph nodes followed by submandibular lymph nodes. 


\begin{tabular}{|c|c|c|}
\hline Aspirate & Frequency & Percent \\
\hline Bloody & 45 & 45.0 \\
\hline Cheesy & 25 & 25.0 \\
\hline Pus like & 30 & 30.0 \\
\hline \multicolumn{3}{|c|}{ Table 4. Colour of Aspirate } \\
\hline
\end{tabular}

Blood mixed aspirates were most commonly seen in $45 \%$ of total cases followed by pus-like material in $30 \%$ of cases.

\begin{tabular}{|c|c|}
\hline Cytological Diagnosis & Incidence \\
\hline Generalised lymphadenopathy & 33 \\
\hline Tuberculous lymphadenopathy & 40 \\
\hline Hodgkin's lymphoma & 1 \\
\hline Reactive hyperplasia & 13 \\
\hline Non-specific & 8 \\
\hline Carcinoma & 5 \\
\hline Table 5. Incidence of Lymph Node Diseases \\
\hline
\end{tabular}

\begin{tabular}{|c|c|c|}
\hline Age & Frequency & Percent \\
\hline $20-30$ & 41 & 41.0 \\
\hline $31-40$ & 27 & 27.0 \\
\hline $41-50$ & 18 & 18.0 \\
\hline$>50 \quad 14$ & 14.0 \\
\hline \multicolumn{2}{|c|}{ Table 6. Age-Wise Distribution } \\
\hline
\end{tabular}

Mean age is 35.64 years. Out of 100 cases, 41 cases were in the age group of 20 - 30 yrs.

\begin{tabular}{|c|c|c|c|c|c|c|c|}
\hline & \multicolumn{4}{|c|}{ Age (in Years) } & \multirow{2}{*}{ Total } & \multirow{2}{*}{$\begin{array}{c}\text { Chi- } \\
\text { Square } \\
\text { value }\end{array}$} & \multirow{2}{*}{$\begin{array}{c}P \\
\text { value }\end{array}$} \\
\hline & $20-30$ & $31-40$ & $41-50$ & $>50$ & & & \\
\hline $\mathrm{CA}$ & 0 & 1 & 2 & 2 & 5 & \multirow{7}{*}{27.7} & \multirow{7}{*}{0.023} \\
\hline GL & 14 & 10 & 5 & 4 & 33 & & \\
\hline HL & 0 & 0 & 1 & 0 & 1 & & \\
\hline NS & 3 & 3 & 1 & 1 & 8 & & \\
\hline RH & 9 & 1 & 2 & 1 & 13 & & \\
\hline TL & 15 & 12 & 7 & 6 & 40 & & \\
\hline Total & 41 & 27 & 18 & 14 & 100 & & \\
\hline
\end{tabular}

It would be observed that the incidence of tuberculous lymphadenitis have increased in age group of $20-30$ followed by $31-40$ years of age group. $P<0.05$, i.e. statistically significant association between age and diagnosis.

\begin{tabular}{|c|c|}
\hline Cytomorphological Pattern & Number (\%) \\
\hline Epithelioid granuloma with caseous necrosis & $6(\%)$ \\
\hline Epithelioid granuloma without necrosis & $5(\%)$ \\
\hline Necrosis only without granuloma & $17(\%)$ \\
\hline Polymorphs with necrosis & $12(\%)$ \\
\hline
\end{tabular}

Most common cytomorphological pattern was necrosis only without granulomas in $17 \%$ of cases and polymorphs with necrosis in $12 \%$ of cases.

\begin{tabular}{|c|c|c|c|c|c|}
\hline & $\begin{array}{c}\text { AFB } \\
\text { Positive }\end{array}$ & $\begin{array}{c}\text { AFB } \\
\text { Negative }\end{array}$ & Total & \begin{tabular}{|c} 
Chi- \\
Square \\
Value \\
\end{tabular} & $\begin{array}{c}P \\
\text { value }\end{array}$ \\
\hline $\begin{array}{c}\text { Epithelioid } \\
\text { granuloma with } \\
\text { caseous necrosis }\end{array}$ & 6 & 0 & 6 & \multirow{4}{*}{6.01} & \multirow{4}{*}{0.111} \\
\hline $\begin{array}{c}\text { Epithelioid } \\
\text { granuloma } \\
\text { without necrosis } \\
\end{array}$ & 5 & 0 & 5 & & \\
\hline $\begin{array}{c}\text { Necrosis only } \\
\text { without } \\
\text { granuloma }\end{array}$ & 13 & 4 & 17 & & \\
\hline $\begin{array}{c}\text { Polymorphs with } \\
\text { necrosis }\end{array}$ & 12 & 0 & 12 & & \\
\hline $\begin{array}{r}\text { Table } 9 . \\
\text { Cytomorp }\end{array}$ & $\begin{array}{l}\text { rrelat } \\
\text { ologice } \\
\text { Lyn }\end{array}$ & aden & sitiv & $\begin{array}{l}\text { with } \\
\text { culous }\end{array}$ & \\
\hline
\end{tabular}

FNAC of lymph node shows $100 \%$ positivity in smears revealing polymorphs with necrosis, epithelioid granuloma with necrosis and epithelioid granulomas without necrosis, while the lowest was seen in necrosis only without epithelioid granuloma (76.4\%). However, it was statistically insignificant.

\section{DISCUSSION}

Fine needle aspiration cytology of lymph node has become an integral part of initial diagnosis and management of patients with lymphadenopathy due to early availability of result, simplicity and minimal trauma with less complication..$^{9}$ FNAC has also been advocated as a useful method in comparison to more expensive surgical excision biopsies in developing countries with limited financial and health care resources. ${ }^{10}$ It almost offers an accurate diagnosis for reactive lymphoid hyperplasia, infectious disease, granulomatous lymphadenitis and metastatic malignancy. Thus, it can avoid the need for excisional biopsy in most cases and allow rapid onset of therapy. ${ }^{11}$

In this study a total number of 100 cases of lymphadenopathy were studied, out of which $95 \%$ were benign and 5\% were malignant. Ahmad et al $2005^{12}$ showed benign causes contributed to $86.4 \%$ of lymphadenopathies. Studies from other developing countries like Pakistan (Fatima et al 2011,13 Khan et al 2011) also reported 92\% and $73.2 \%$ benign lymphadenopathies.

In our study, most common lesion on cytology was found to be tuberculous lymphadenitis (40\%). The result was comparable to study done by Khajuria $\mathrm{R}$ et al ${ }^{14}$ in 2006 , whereas Mohanty et al, ${ }^{15}$ Kochhar K et al ${ }^{16}$ and Adhikari P et $\mathrm{al}^{17}$ did the same study and found reactive hyperplasia to be the most common.

We noted slightly lower incidence of $40 \%$ of tuberculosis cases. There are wide variations in the prevalence of TB lymphadenitis, which may be due to variation in geographical prevalence of TB, age and immunological status of patients selected. Sarda et $\mathrm{al}^{18}$ reported $80 \%$ of enlarged nodes to be tuberculous in origin. Similar high incidence was reported by Jha et $\mathrm{al}^{19}(63 \%)$, Mahajan et $\mathrm{al}^{20}(54 \%)$, Dandapat et $\mathrm{al}^{21}$ (41.5\%), Castro et al ${ }^{22}$ (46\%), Ahmad et al ${ }^{12}$ (38\%) and Tilak et $\mathrm{al}^{23}(38.8 \%)$. In the present study, the lesions were seen in all age groups ranging from 20 years with a mean age of 35.64 years. Maximum cases were seen between 20 - 30 years similar to study done by Dukare SR et al ${ }^{24}$ and 
Chandanwale $\mathrm{S}$ et $\mathrm{al}^{25}$ where Sharma $\mathrm{P}$ et $\mathrm{al}^{26}$ reported maximum no. of cases during 11 - 20 years.

Tuberculous lymphadenitis peak age incidence was seen during 2 nd decade. 15 cases out of 40 (55.6\%) cases of tuberculosis lymphadenitis were recorded. Similar findings were seen in study done by Khajuria R et al.14

The most common age group which presented with lymphadenopathy was between 20 - 30 years of age followed by $31-40$ years, 41 - 50 years and more than 50 years; majority of patients were in the second to fourth decades of life in studies by Paliwal et al, ${ }^{27}$ Ergete and Bekele et al, ${ }^{28}$ Purohit et al,29 Dandapat et $\mathrm{al}^{21} \mathrm{Ahmad}^{2}$ et al ${ }^{12}$ and Hemlata et al. $^{30}$

Out of 100 cases, $46 \%$ were males and $54 \%$ were females with significant female preponderance; 23:27 (M: F) sex ratio was observed in our study. This may be because of malnutrition and overall low living standards among females in this area. Female preponderance has also been observed by Fatima et al, ${ }^{13}$ Paliwal et al, ${ }^{27}$ Ergete and Bekele et al, ${ }^{28}$ Purohit et $\mathrm{al}^{29}$ Chand et $\mathrm{al}^{31}$ and Pamra et al. ${ }^{32}$ Male predominance was noticed by Ahmad et al $^{12}$ and Rajsekaran et al. ${ }^{33}$

In our study, cervical lymph nodes (70\%) were frequently involved followed by 9\% Submandibular, 8\% Submental, 3\% Neck, 1\% Inguinal, 1\% Mandible and 1\% Chest wall and 1\% Breast and 1\% Abdominal wall. This was in concordance with Bezabih et $\mathrm{al}^{34}$ who observed cervical involvement in $74.2 \%$ of cases. Khajuria $\mathrm{R}$ et al ${ }^{14}$ also found cervical lymph node to be most commonly involved. Hirachand et al ${ }^{35}$ showed $74.6 \%$ involvement of cervical lymph nodes by various lesions. Many others (Pandit et $\mathrm{al}^{36}$ 1987: Ahmad et al ${ }^{12}$ 2005: Nidhi et al, 2011) also found cervical region to be the most common site of involvement.

Most common cytological pattern seen was necrosis only without granulomas in $17 \%$ of cases and polymorphs with necrosis in $12 \%$ of cases. While in a study by Gupta et al,37 epithelioid clusters with or without Langhans giant cells with necrosis was most commonly observed cytological pattern in $50.35 \%$ cases. ZN staining for acid fast bacilli was seen in $90 \%$ cases, Ergete and Bekele et al ${ }^{28}$ reported $71.7 \%$, Chand et al ${ }^{31}$ reported $44.54 \%$, Bezabih et al ${ }^{34}$ reported $59.5 \%$, Dasgupta et al ${ }^{38}$ reported $45.6 \%$ AFB positivity in their studies. On the other hand, a low positivity rate of AFB positivity of (19.6\% cases) on ZN staining was reported by Agarwal et al in their study.

High AFB positivity noted in our study may be because of extensive screening done as in addition to one $\mathrm{ZN}$ stained smear in each case, we got ZN staining done on second smear or decolourised smear where cytology suggested tuberculosis, especially when necrosis was present.

According to gross nature of aspirate, blood mixed aspirates were noted in $45 \%$ followed by purulent/ pus material in $30 \%$ and caseous/ cheesy material in $25 \%$ cases in current study, whereas Hemalatha et al ${ }^{30}$ observed blood mixed aspirates in $87.3 \%$ and purulent-to-cheesy material in $12.7 \%$ cases.

\section{CONCLUSION}

In conclusion, it was found that female predominance was observed in our study. Commonest lymph node involved was cervical followed by submandibular. Most common lesion on cytology was found to be tuberculous lymphadenitis (40\%) followed by generalised lymphadenopathy (33\%), reactive hyperplasia (13\%), non-specific $(8 \%)$ metastatic carcinoma (5\%) and Hodgkin's lymphoma (1\%). In gender-wise classification, tuberculous lymphadenitis was 27 in females and 13 in males. It can be concluded that FNAC can be performed as outpatient department procedure, it is cost effective and requires minimum instrumentation in comparison to excision biopsy. Using FNAC diagnostic accuracy is high in tuberculous lymphadenopathy. Therefore, even in most remote areas, FNAC can be used for diagnosing tuberculous lymphadenopathy. Coupling FNAC with ZN staining increases the diagnostic accuracy. Diagnostic accuracy can be further increased by submitting some material obtained by FNA for culture.

\section{REFERENCES}

[1] Chaturvedi NK, Singh JP, Anita D. Fine needle aspiration cytology in the diagnosis of tuberculous lymphadenitis. Indian J Pathol Microball 1989;32(2):101-4.

[2] Darnal HK, Karim N, Kamini K, et al. The profile of lymphadenopathy in adults and children. Med J Malaysia 2005;60(5):590-8.

[3] Ahmed N, Israr S, Ashraf MS. Comparison of fine needle aspiration cytology (FNAC) and excision biopsy in the diagnosis of cervical lymphadenopathy. Pakistan J Surg 2009;25(2):72-5.

[4] Khan AH, Hayat AS, Baloch GH, et al. Study on the role of fine needle aspiration cytology in cervical lymphadenopathy. World Applied Sci J 2011;12(11):1951-4.

[5] Steel BL, Schwartz MR, Ramzy I. Fine needle aspiration biopsy in diagnosis of lymphadenopathy in 1,103 patients. Role, limitations and analysis of diagnostic pitfalls. Acta Cytol 1995;39(1):76-81.

[6] Hafez NH, Tahoun NS. Reliabiity of fine needle aspiration cytology (FNAC) as a diagnostic tool in cases of cervical lymphadenopathy. J Egyptian Natl Cancer Institute 2011;23(3):105-14.

[7] Kumar V, Abbas AK, Fausto N, et al. Robbins basic pathology. $8^{\text {th }}$ edn. Philadelphia: Elsevier Saunders 2007: p. 516-22.

[8] Ramachandran R, Paramasivan CN. What is new in the diagnosis of tuberculosis? Part 1: Techniques for diagnosis of tuberculosis. Indian $\mathrm{J}$ Tuberc 2003;50:133-42.

[9] Keith VE, Harsharan SK, Jerald GZ. Fine needle aspiration biopsy of lymph nodes in the modern era: reactive lymphadenopathies. Pathol Case Rev 2007;12(1):27-35.

[10] Das DK. Value and limitations of fine-needle aspiration cytology in diagnosis and classification of lymphomas: a review. Diagn Cytopathol 1999;21(4):240-9.

[11] Howlett DC, Harper B, Quante M, et al. Diagnostic adequacy and accuracy of fine needle aspiration cytology in neck lump assessment: results from a regional cancer network over a one year period. J Laryngol Otol 2007;121(6):571-9.

[12] Ahmad SS, Akhtar S, Akhtar K, et al. Study of fine needle aspiration cytology in lymphadenopathy with special reference to Acid-fast staining in cases of tuberculosis. JK Science 2005;7(1):1-4. 
[13] Fatima S, Arshad S, Ahmed Z, et al. Spectrum of cytological findings in patients with neck lymphadenopathy--experience in a tertiary care hospital in Pakistan. Asian Pac J Cancer Prev 2011;12(7):1873-5.

[14] Khajuria R, Goswami KC, Singh K, et al. Pattern of lymphadenopathy on fine needle aspiration cytology in Jammu. JK Sci 2006;8(3):157-9.

[15] Mohanty R, Wilkinson A. Utility of fine needle aspiration of lymph nodes. IOSR J Dent \& Med Sci 2013;8(5):13-8.

[16] Kochhar AK, Duggal G, Singh K, et al. Spectrum of cytological findings in patients with lymphadenopathy in rural population of south Haryana, India: experience in a tertiary care hospital. Internet J Patthol 2012;13(2):8.

[17] Adhikari P, Sinha BK, Baskota DK. Comparison of Fine needle aspiration cytology and histopathology in diagnosing cervical lymphadenopathies. Australas Med J 2011;4(2):97-9.

[18] Sarda AK, Bal S, Singh MK, et al. Fine needle aspiration cytology as a preliminary diagnostic procedure for asymptomatic cervical lymphadenopathy. J Assoc Physicians India 1990;38(3):203-5.

[19] Jha BC, Dass A, Nagarkar N, et al. Cervical tuberculous lymphadenopathy: changing clinical pattern and concepts in management. Postgrad Med J 2001;77(905):185-7.

[20] Mahajan M, Hirachan S, Kafle PK, et al. Incidence of tuberculosis in enlarged neck nodes, our experience. Kathmandu University Medical Journal 2009;7(25):548.

[21] Dandapat MC, Panda BK, Patra AK, et al. Diagnosis of tubercular lymphadenitis by fine needle aspiration cytology. Indian J Tuberc 1987;37:139-42.

[22] Castro DJ, Hoover L, Castro DJ, et al. Cervical mycobacterial lymphadenitis. Medicl vs surgical management. Arch Otoryngol 1985;111(12):816-9.

[23] Tilak V, Dhaded AV, Jain R. Fine needle aspiration cytology of head and neck masses. Ind J Pathol Microbiol 2002;45(1):23-9.

[24] Dukare SR, Jadhav DS, Gaikwad AL, et al. Fine needle aspiration cytology of cervical lymphadenopathy - a study of 510 cases. Asian J Sci Technol 2014;5(9):53740.

[25] Chandanwale S, Buch A, Verma A, et al. Evaluation of granulomatous lymphadenitis on Fine needle aspiration cytology-diagnostic dilemma. Int J Pharm Bio Sci 2014;5(4):377-84.
[26] Sharma P, Rana S, Gill MK, et al. Spectrum of Lymph node lesions on cytology in rural Haryana - a retrospective analysis. International Journal of Research in Medical Sciences 2015;3(5):1125-30.

[27] Paliwal N, Thakur S, Mullick S, et al. FNAC in tubercular lymphadenitis: experience from tertiary level referral centre. Indian J Tuberc 2011;58(3):1027.

[28] Ergete W, Bekele A. Acid fast bacilli in aspiration smears from tuberculosis patients. Ethiop J Health Dev 2000;14(1):99-104.

[29] Purohit MR, Mustafa T, Morkve O, et al. Gender differences in the clinical diagnosis of tuberculous lymphadenitis - a hospital based study from central India. International Journal of Infectious Diseases 2009;13(5):600-5.

[30] Hemalatha A, Shruti PS, Kumar MU, et al. Cytomorphological patterns of tubercular lymphadenitis revisited. Ann Med Health Sci Res 2014;4(3):393-6.

[31] Chand P, Dogra R, Chauhan N, et al. Cytopathological pattern of tubercular lymphadenopathy on FNAC: analysis of 550 consecutive cases. J Clin Diagn Res 2014;8(9):FC16-FC9.

[32] Pamra SR, Baily GV, Gupta SP; Cervical lymphadenopathies. Indian J Tuberc, 1987;34:96-100.

[33] Rajsekaran S, Gunasekaran M, Jayakumar DD, et al. Tuberculous cervical lymphadenitis in HIV positive and negative patients. Indian J Tubberc 2001;48:2014.

[34] Bezabih M, Mariam DW, Selassie SG. Fine needle aspiration cytology of suspected tuberculous lymphadenitis. Cytopathology 2002;13(5):284-90.

[35] Hirachand S, Lakhey M, Akhter J, et al. Evaluaion of fine needle aspiration cytology of lymph nodes in Kathmandu Medical College, teaching hospital. Kathmandu Univ Med J 2009;7(26):139-42.

[36] Pandit AA, Candes FP, Khubchandani SR. Fine needle aspiration cytology of lymph nodes. J Postgrad Med 1987;33(3):134-6.

[37] Gupta AK Nayar M, Chandra M. Critical appraisal of fine needle aspiration cytology in tuberculous lymphadenitis. Acta Cytol 1992;36(3):391-4.

[38] Dasgupta A, Ghosh RN, Poddar AK, et al. Fine needle aspiration cytology of cervical lymphadenopathy with special reference to tuberculosis. J Indian Med Assoc 1994;92(2):44-6. 